\title{
Special Issue on Mobile IoT: Enabling Technologies and Trends
}

\author{
Liljana Gavrilovska' ${ }^{1}$ Dina Simunic $^{2} \cdot$ Milica Pejanović-Djurišićc ${ }^{3}$
}

Published online: 12 October 2017

(C) Springer Science+Business Media, LLC 2017

The trends and recent developments in wireless and mobile ecosystems envision tremendous growth of new solutions and technologies, services and applications. Two major paradigms are moving this wave forward: the upcoming $5 \mathrm{G}$ era and fast penetrating internet of everything (IoE). This growth inevitably affects all domains of our being, actively involving research and industrial communities.

A plethora of enabling technologies emerged focusing to fulfill more strict requirements towards the diversified QoS, energy efficiency, security mechanisms, etc. Moreover, a huge number of new smart devices emerged on the market. Worldwide daily adoption and innovation of different mobile devices, tending to get smaller and richer with offering more applications are constantly changing the technology landscape. Following this tremendous and demanding growth, the vendors and service providers are forcing to develop new solutions, offer new services and networking paradigms, and create new business models that affects different areas of our everyday life, such as healthcare, transport, agriculture, commerce, defense, etc. All these developments continuously change the technology landscape into more intelligent and smart environment where the mobile users can experience improved everyday life.

This special issue is mainly composed of the extended versions of selected papers presented at the 4th Center of TeleInFrastrukture-South-East Europe (CTIF SEE) Workshop: "Mobile IoT: Enabling technologies and trends", 12-13 September 2016, Skopje, Macedonia. It also includes selected papers following the call for submissions of

Liljana Gavrilovska

liljana@feit.ukim.edu.mk

Dina Simunic

Dina.Simunic@fer.hr

Milica Pejanović-Djurišić

milica@t-com.me

1 Ss. Cyril and Methodius University in Skopje, Skopje, Macedonia

2 University of Zagreb, Zagreb, Croatia

3 University of Montenegro, Podgorica, Montenegro 
original research papers, both theoretical and practice-oriented, from academia, industrial professionals and students from various engineering fields aiming to present innovative approaches and ideas in the field. This issue covers different aspect from particular solutions for PHY layer and advanced networking to applications and overall smart system design.

Finally, we would like to thank all the authors for their contributions, the reviewers for their valuable time and effort, the members of the editorial team of the journal for their constructive help and support. Without this joint effort and commitment this issue could not be prepared.

The guest editors, Liljana Gavrilovska, Dina Simunic and Milica Pejanović-Djurišić.

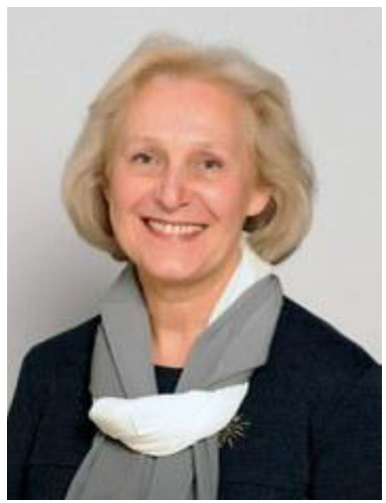

Liljana Gavrilovska currently holds the positions of full professor, Head of the Center for Wireless and Mobile Communications (CWMC) and the Wireless Networking Group at the Faculty of Electrical Engineering and Information Technologies, Ss Cyril and Methodius University (UKIM) in Skopje. She is also the founder and head of the research Wireless Networking Group. Prof. Gavrilovska participated in numerous EU funded projects such as ASAP, PACWOMAN, MAGNET, MAGNET Beyond, ARAGORN, ProSense, FARAMIR, QUASAR, ACROPOLIS, and eWall, NATO funded projects such as RIWCoS and ORCA and several domestic research and applicative projects. She is author/co-author of more than 200 research journal and conference publications and technical papers, a co-author of the book Ad Hoc Networking Towards Seamless Communications (Springer, 2006) and co-editor of the book Application and Multidisciplinary Aspects of Wireless Sensor Networks (Springer, 2010). Her major research interest is concentrated on cognitive radio networks, future mobile systems, virtualization and SDN, wireless and personal area networks, cross-layer optimizations, ad-hoc networking, traffic analysis and heterogeneous wireless networks.

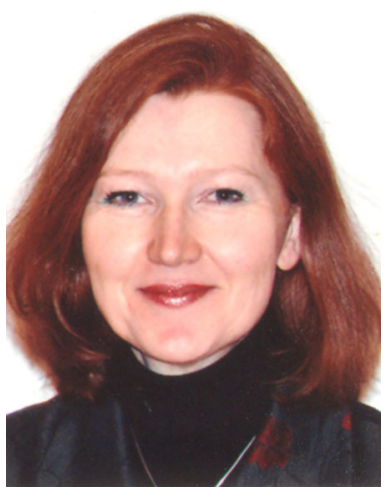

Dina Simunic is a full professor at University of Zagreb, Faculty of Electrical Engineering and Computing. She finished Dipl-Ing. and M.Sc. E.E. at University of Zagreb, Faculty of Electrical Engineering and Computing, in Zagreb, Croatia. She completed doctorate at Graz University of Technology in Graz, Austria in 1995. Dr. Simunic became Ass.Prof in 1996 at University of Zagreb, Faculty of Electrical Engineering and Computing in Zagreb, Croatia. She got the best awards for young scientists at three international congresses. In 1997 she became vice-chair of paneuropean project COST 244bis: "Biomedical Effects of Electromagnetic Fields". From 2001 to 2004 she served as vice-chair of Telecommunications Council of Republic of Croatia. From 2006 to 2014 she served as vice-chair of Domain Committee for Information and Communication Technologies at COST precompetitive 6th and 7th scientific framework of European commission. Dr. Simunic was a guest professor in research laboratories of companies "Wandel\&Goltermann" and "Motorola Inc.". She was reviewer of scientific projects of the European Fifth and Sixth framework. She was participating in the IEEE and IEC Standardization Committees, as well as in the project with US FDA on Bluetooth and WLAN. She has excellent cooperation with Croatian telecom industry. Research results she publishes in the international journals, as well as on the international congresses. She is serving as chair of Technical Committee for "Standardization in Telecommunications" of Croatian Standardization Institute. She was a member of Erasmus Mundus project, as well as leader of work package in FP7 project: "eWALL for Active Long Living". She is lecturing "Technical standardization and legislation", "Economy and Ecology of Electromagnetic Fields", "Biomedical Effects of Electromagnetic Fields" and "Wireless Communications". 


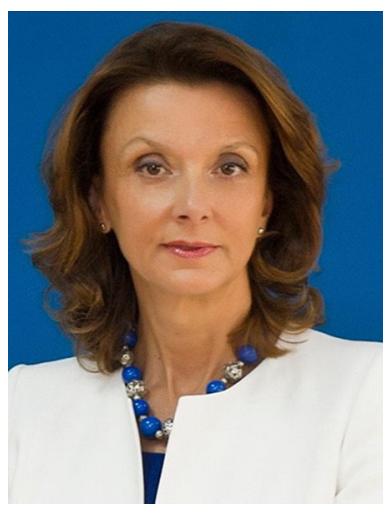

Milica Pejanović-Djurišić is full professor in telecommunications at the University of Montenegro, Faculty of Electrical Engineering, Podgorica, Montenegro. She is also director of the Research Center for Info-Communication Technologies, founded with the aim to foster innovation based research at the University of Montenegro. Its flagship project is BIO-ICT Centre of Excellence in BIoInformatics, which is the first centre of excellence in Montenegro. Prof. Pejanović-Djurišić has been teaching telecommunications courses on graduate and postgraduate levels, as well as courses in mobile communications and computer communications and networks, being the author of four books and many strategic studies. She has published more than 200 scientific papers in peer-reviewed international and national journals and conference proceedings, being the author of four books and a number of book chapters. Her main research interests are: wireless communications, 5G wireless networks, wireless IoT, cooperative and energy efficient transmission techniques, ICT trends and applications, optimization of telecommunication development policy.

has considerable industry and operating experiences working as industry consultant (Ericsson, Siemens) and Telecom Montenegro Chairman of the Board. She has been in charge of wireless networks design and implementation in Montenegro and in the region of SEEurope. Prof. Pejanović-Djurišić has been leading and coordinating many internationally and EU funded ICT projects and initiatives. She is a member of IEEE and IEICE, with a long engagement in the field of telecommunication regulation and standardization. Thus, in addition to work on national and regional levels, she has participated, in cooperation with ITU, in a number of missions and activities related with regulation issues, development strategies and new technological solutions. 